\title{
Susceptibility of Normal and Transformed Cell Lines to Cytostatic and Cytocidal Effects Exerted by Macrophages
}

\author{
Keller, R
}

\begin{abstract}
Activated, nonimmune macrophages exerted profound effects on the proliferation and viability of eukaryotic target cells in vitro. Pronounced macrophage-mediated cytostasis was exerted on every rapidly proliferating cell line examined, irrespective of transformation, species derivation, cell type, or growth characteristics. However, the magnitude of cytostasis effected differed markedly among the 40 cell lines tested. There was no evident correlation between susceptibility to cytostasis and degree of transformation. Transformed cell lines with high and with low malignant attributes were affected equally. A comparable pattern was discerned for cytocidal effects of macrophages, in which the susceptibility of transformed targets was independent of the degree of malignancy
\end{abstract}

DOI: https://doi.org/10.1093/jnci/56.2.369

Posted at the Zurich Open Repository and Archive, University of Zurich

ZORA URL: https://doi.org/10.5167/uzh-155051

Journal Article

Published Version

Originally published at:

Keller, R (1976). Susceptibility of Normal and Transformed Cell Lines to Cytostatic and Cytocidal Effects Exerted by Macrophages. Journal of the National Cancer Institute, 56(2):369-374.

DOI: https://doi.org/10.1093/jnci/56.2.369 


\title{
Susceptibility of Normal and Transformed Cell Lines to Cytostatic and Cytocidal Effects Exerted by Macrophages ${ }^{1,2}$
}

\author{
R. Keller ${ }^{3,4}$
}

\begin{abstract}
SUMMARY-Activated, nonimmune macrophages exerted profound effects on the proliferation and viability of eukaryotic target cells in vitro. Pronounced macrophage-mediated cytostasis was exerted on every rapidly proliferating cell line examined, irrespective of transformation, species derivation, celI type, or growth characteristics. However, the magnitude of cytostasis effected differed markedly among the 40 cell lines tested. There was no evident correlation between susceptibility to cytostasis and degree of transformation. Transformed cell lines with high and with low malignant attributes were affected equally. A comparable pattern was discerned for cytocidal effects of macrophages, in which the susceptibility of transformed targets was independent of the degree of malignancy.J Natl Cancer Inst 56: 369-374, 1976.
\end{abstract}

Recent work (1-5) has shown that apart from the important function of mononuclear phagocytes in pathologic processes, the presentation of antigen to immunocompetent cells, and resistance against intracellular microorganisms, mononuclear phagocytes also exert profound effects on eukaryotic cells. These in vitro studies have yielded voluminous data indicating that activated, nonimmune macrophages (AM) can affect target cells in a variety of ways, and that they can discriminate between normal and transformed cells and resting and replicating cells. These destructive capabilities apparently involve the metabolic state of a macrophage population, as well as the proportion of effectors to targets. The findings thus far indicated that the cytostatic effects on targets exerted by AM are independent of target species (syngeneic, allogeneic, or xenogeneic), target cell type (epithelial or lymphoid), target growth characteristics (monolayer or suspension), or transformation (normal vs. neoplastic tissue) $(4-7)$. There is general agreement $(1-4,8-10)$ that interaction of $A M$ with tumor targets results in an altered morphology and decrease in the number of cells, attesting to the AM's capacity to kill tumor targets in vitro. However, further investigation on many cell lines derived from normal and transformed tissue disclosed that macrophage cytocidal target cell effects are not invariably correlated with the malignant attributes of cell lines derived from transformed tissue. $.^{5}, 8$ The present work further explores whether the macrophage-mediated cytocidal effect is selective for tumors.

\section{MATERIALS AND METHODS}

Target cell lines.- Rat: Cells derived from normal rat kidney (NRK) and rat kidney cells infected with $B_{77}$ Rauscher murine leukemia virus $\left(B_{77}=\right.$ NRK) (11), a gift from Dr. T. Graf, were grown in Eagle's minimum essential medium (MEM) (12) modified as follows: $280 \mathrm{mg}$ glutamine/liter, $100 \mathrm{mg}$ calcium/liter, $1 \mathrm{~g} \mathrm{NaHCO}_{3} /$ liter, $2 \mathrm{~g}$ glucose/liter, and $1 \mathrm{mg}$ biotin/liter, and supplemented with $100 \mathrm{U}$ penicillin $/ \mathrm{ml}, 50 \mu$ streptomycin $/ \mathrm{ml}$ (modified MEM), 10\% fetal calf serum (FCS), and 10\% tryptose phosphate (Difco Laboratories, Detroit, Mich.). DA rat tumors were those described in (4) or were newly induced with polyoma virus, dimethylbenz $[a]$ anthracene
(DMBA), or 3-methylcholanthrene (MCA). These tumor cells were grown in modified MEM supplemented with $10 \%$ newborn calf serum (NCS). DA rat adult and embryo fibroblasts were repeatedly newly established (6) and grown in modified MEM supplemented with $10 \%$ FCS.

Mouse: The A9 cell (having little ability to grow progressively in vivo), its highly malignant counterpart A9HT (high incidence of take) (13), and the hybrid cell lines between these $\mathrm{L}$-cell derivatives and malignant mouse tumors, such as Ehrlich (spontaneous carcinoma), SEWA (polyoma-induced sarcoma), MSWBS (MCA-induced sarcoma), and YACIR (an immunoresistant derivative of the YAC tumor, a Moloney virus-induced lymphoma) $(13,14)$, provided by Dr. George Klein, were grown in nonmodified Eagle's MEM. BALB/c3T3 cells and BALB/c simian virus 40 (SV40)-transformed 3T3 cells, originally obtained from Dr. Stuart Aaronson, were maintained in modified MEM with $10 \%$ FCS. Suspension cultures of the transplantable murine mast cell tumor P-815 X2, obtained from Drs. R. Schindler and M. Bertschmann, were grown as described in (15); the medium was supplemented with $10 \%$ NCS instead of horse serum.

Human: Three adherent cell lines derived from human mammary carcinomas were used: BT-20, supplied by Dr. J. Fogh, was grown in modified MEM supplemented with $10 \%$ FCS; MPZ-2 and MPZ-4 were freshly established from a biopsy of human breast cancer, provided by Dr. J. R. Rüttner and grown in modified MEM supplemented with $15 \%$ FCS. Two human melanoma lines were used. SK-melanoma-l (MEL-1) cells, obtained from Dr. K. T. Brunner, were grown in suspension in modified MEM supplemented with 10\% FCS. Melanoma cells (RPMI 7932), provided by Dr. W. D. Terry, were grown in adherent culture in modified MEM with $10 \%$ FCS. SK-OS-5, derived from an osteogenic sarcoma and supplied by Dr. J. Fogh, was grown in adherent culture

\footnotetext{
1 Received June 2, 1975; accepted September 15, 1975.

2 Supported by grants 3.516 .71 and 3.234 .74 from the Swiss $\mathrm{Na}$ tional Science Foundation.

3 Immunobiology Research Group, University of Zurich, Schönleinstrasse 22, CH-8032 Zurich, Switzerland.

* I thank the following colleagues for providing cell lines: $\mathrm{Dr}$. S. Aaronson, National Cancer Institute (NCI), National Institutes of Health (NIH), Bethesda, Md.; Dr. A. C. Allison, Clinical Research Centre, Harrow, England; Dr. M. Bertschmann, Theodor KocherInstitut, Bern, Switzerland; Dr. K. T. Brunner, Institut Suisse des Recherches Expérimentales sur le Cancer, Lausanne, Switzerland, Dr. J. Fogh, Sloan-Kettering Institute for Cancer Research, Rye, N.Y.; Dr. T. Graf, Max Planck-Institut für Virusforschung, Tübingen, W. Germany; Dr. G. Klein, Institute of Tumor Biology, Karolinska Institutet, Stockholm, Sweden; Dr. J. R. Rüttner, Pathologisches Institut, University of Zurich; Dr. Ch. Sauter, Medizinische Universitätshlinik, Kantonsspital, Zurich; Dr. R. Schindler, Pathologisches Institut der Universität, Bern; and Dr. W. D. Terry, NCI, NIH. I also thank Dr. Maurice Landy, Schweizerisches Forschungsinstitut, Davos, Switzerland for his helpful criticism of this manuscript, and Miss R. Keist and Miss E. Müller for their expert technical assistance.

5 Bregnard A, Gehring WJ, Keller $\mathbf{R}$, et al: In preparation.

6 Keller R: Unpublished data.
} 
in modified MEM with 10\% FCS. The Burkitt's lymphoma cell line RAJI, obtained from Dr. G. Klein, was grown in modified MEM supplemented with $10 \%$ FCS. BEN, a tumor cell line producing carcinoembryonic antigen, was supplied by Dr. Ch. Sauter and grown in adherent culture in modified MEM with $10 \%$ FCS. Cell lines were repeatedly checked for the possibility of mycoplasma contamination, but none was found.

Origin, culture conditions, and properties of other cell lines used were described in (6).

Macrophage monolayers were prepared as described in $(4,6)$. Peptone-induced peritoneal cells from inbred DA rats were seeded into plastic petri dishes. After 30 minutes at $37^{\circ} \mathrm{C}$, the nonadhering cells were removed by intensive washing. After this procedure, at least $96 \%$ of the cells in the monolayer of approximately $2 \times 10^{6}$ cells showed the characteristics of macrophages. To these macrophage monolayers, target cells $\left(2 \times 10^{5} /\right.$ dish) were immediately added and the cultures were maintained at the appropriate temperature in a humid atmosphere of $5 \% \mathrm{CO}_{2}$ and $95 \%$ air.

Measurement of cytostasis.-Residual target cell proliferation was assessed after varying intervals of macrophage-target cell interaction by: 1) exposure for $60 \mathrm{~min}$ utes at $37^{\circ} \mathrm{C}$ to $1 \mu \mathrm{Ci}{ }^{3} \mathrm{H}$-methylthymidine $\left({ }^{3} \mathrm{H}-\mathrm{TDR}\right) /$ dish $(5,000 \mathrm{mCi} / \mathrm{mmole}$; The Radiochemical Centre, Amersham, Buckinghamshire, England), and processing as described in $(4,6)$; or 2) by exposure for 8 hours at $37^{\circ} \mathrm{C}$ to $0.1 \mu \mathrm{Ci}{ }^{125} \mathrm{I}$-5-iodo-2'-deoxyuridine (125IUDR, sp act, 8-10 $\mu \mathrm{Ci} / \mu \mathrm{g}$; The Radiochemical Centre). After careful washing, the cells were washed twice with $1.5 \%$ perchloric acid and radioactivity was measured in an automatic gamma counter (Tracerlab, Inc., Waltham, Mass.).

Assessment of target cell viability.-Two methods were used to assess target cell viability. In experiments performed to assess the capacity of target cells to reestablish growth, $2 \times 10^{5}$ targets were cultured in the presence of $2 \times 10^{6}$ AM (6). After 72 hours, the cells were harvested by trypsinization, washed, counted, and diluted to a concentration of $300 / 3.5 \mathrm{ml}$; aliquots of this volume were also dispensed to 30-ml Falcon culture flasks. After 10 days' incubation in $5 \% \mathrm{CO}_{2}$ at $37^{\circ} \mathrm{C}$, we assessed target cell proliferation by adding $1 \mu \mathrm{Ci}{ }^{3} \mathrm{H}$-TDR for $60 \mathrm{~min}$ utes at $37^{\circ} \mathrm{C}$ and by processing the cells as described. Lines derived from the A9 cell were easily distinguished morphologically from AM. Thus the number of target cells remaining in culture after a 72-hour interaction with AM could be counted after trypsinization.

In other experiments, the release of ${ }^{125}$ IUDR from prelabeled targets was a measure of macrophage-mediated target cell damage. Subconfluent cultures of target cells grown in 250-ml Falcon tissue culture flasks containing $10 \mathrm{ml}$ medium were pulsed for 8 hours with $1 \mu \mathrm{Ci}$ ${ }^{125} \mathrm{IUDR} /$ flask $(0.1 \mu \mathrm{Ci} / \mathrm{ml})$ in the presence of 2 '-fluoro-5deoxyuridine (FUDR) at a concentration of $10^{-5} \mathrm{M}$. The FUDR, a known inhibitor of thymidylate synthetase, was included to increase ${ }^{125}$ IUDR incorporation into DNA (16), in place of ${ }^{3} \mathrm{H}$-TDR.

In many target cell lines, incubation with a combination of ${ }^{125}$ IUDR and FUDR in the concentrations and time indicated resulted in adequate specific labeling without marked signs of toxicity; these particular cell lines were used here. Following incubation with ${ }^{125}$ IUDR for 8 hours, the cells were washed twice with phosphatebuffered saline to remove unincorporated isotope. The prelabeled cells $\left(2 \times 10^{5} / \mathrm{dish}\right)$ were then added to macrophage monolayers and incubated for varying intervals, after which the cells were removed by a pipette and then centrifuged. Supernatants and cells were enumerated separately in an automatic Tracerlab gamma counter. Results are expressed as a percent of cytocidal capacity, calculated as follows:

$$
\frac{\text { Experimental } \mathrm{dpm}-\text { control } \mathrm{dpm}}{\text { total dpm }} \times 100,
$$

where $\mathrm{dpm}=$ disintegrations per minute.

\section{RESULTS}

\section{Cytostatic Target Cell Effects Mediated by Macrophages}

Following interaction for different intervals with 10 macrophages per target cell, the ${ }^{3} \mathrm{H}-\mathrm{TDR}$ incorporation, a measure of residual target cell proliferative capacity, was profoundly diminished in all of the target cell lines examined (table 1). However, there were considerable differences in the susceptibility of different target cell lines to macrophage-mediated cytostasis. Proliferation of several cell lines (i.e., polyoma virus-induced syngeneic rat tumor cells, xenogeneic mouse SV403T3, and especially P-815 mastocytoma cells) was blocked even in the early phase of interaction and remained at a very low rate as interaction proceeded. Other cell lines were initially more resistant to macrophage-mediated cytostasis but were inhibited during the later phases of interaction; this was seen with 3T3, RPMI 7932, BEN, BT-20, MPZ-2, MPZ-4, SK-OS, and MEL-1 cells. Proliferation of RAJI and several other human lymphoblastoid cell lines was often enhanced in the early phase of interaction with macrophages, but was subsequently diminished as the interaction proceeded. DMBA- and MCA-induced syngeneic rat tumor cells, although effectively inhibited in the early phase, retained proliferative capacity during continuous interaction with macrophages. Proliferation of fibroblasts, derived from rat embryo (or adult) tissues and exposed to macrophages during in vitro passages 4-7 and 24-30, was distinctly diminished in the early phase but often remained unchanged or was even enhanced as interaction proceeded; such reversed reaction to macrophages was observed especially with recently explanted fibroblasts. Thus in all target cell lines examined, pro-

TABLE 1.-Marked inhibition of proliferation of normal and neoplastic target cells $\left(2 \times 10^{5}\right)$ in the presence of $2 \times 10^{6} \mathrm{DA}$ rat macrophages

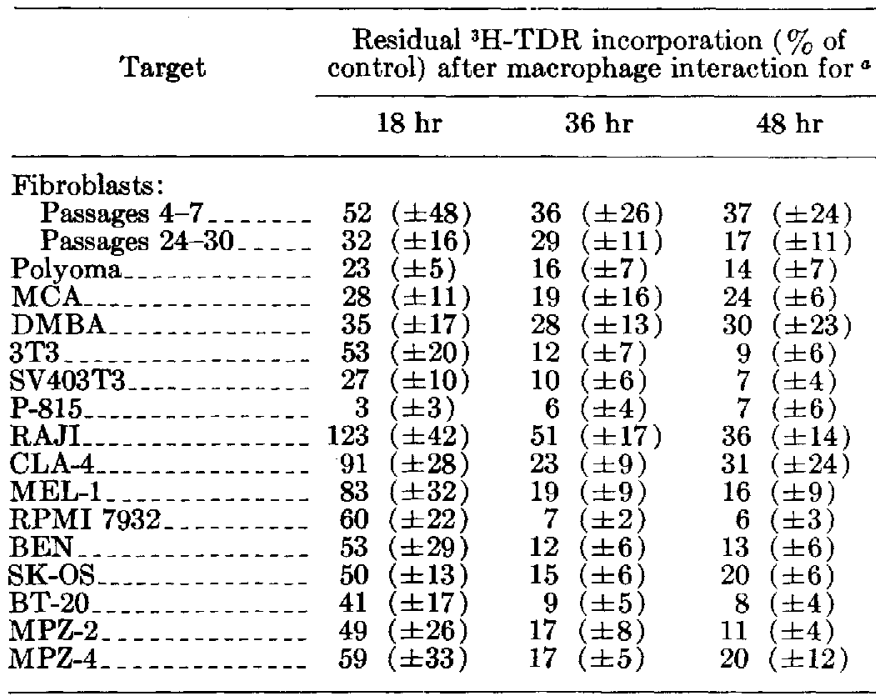

- Values are means ( $\pm \mathrm{sD}$ ) of 10-20 experiments, each performed in triplicate. 
liferation was clearly inhibited when the proportion of macrophages was in the majority, but the pattern of inhibition varied markedly from one cell line to another. Results similar to those with ${ }^{3} \mathrm{H}$-TDR were obtained when targets, which interacted for varying intervals with macrophages, were pulse labeled with ${ }^{125}$ IUDR.

\section{Cytostatic and Cytocidal Macrophage Effects on Targets of Low and High Tumorigenicity}

Enumeration of targets remaining after AM interaction of some lines revealed that, irrespective of whether targets were derived from normal or from transformed tissues, their number decreased as interaction proceeded (text-fig. 1). Since these experiments resolved neither the issue whether macrophage cytostatic and cytocidal effects were related nor whether cytocidal effects were indeed tumor specific, further experiments were made on other cell lines.

Cell lines derived from NKR, its virus-transformed counterpart, and from a temperature-sensitive mutant (ts 339) permissive at $33^{\circ} \mathrm{C}$ but not at $38^{\circ} \mathrm{C}$ (11), provided a useful model to probe the extent to which macrophage-mediated cytostatic and cytocidal effects are related to malignancy. Proliferation rate among these cells differed considerably, but was high enough in each instance to enable reliable quantitation of ${ }^{3} \mathrm{H}$-TDR incorporation into target cell DNA (table 2). These data show that in every one of these cell lines the residual capacity to ${ }^{3} \mathrm{H}-\mathrm{TDR}$ decreased as the period of interaction with AM increased. Moreover, the findings showed that NRK cells, although significantly inhibited, were less susceptible to macrophage-mediated cytostasis than were the transformed lines. However, the transformed

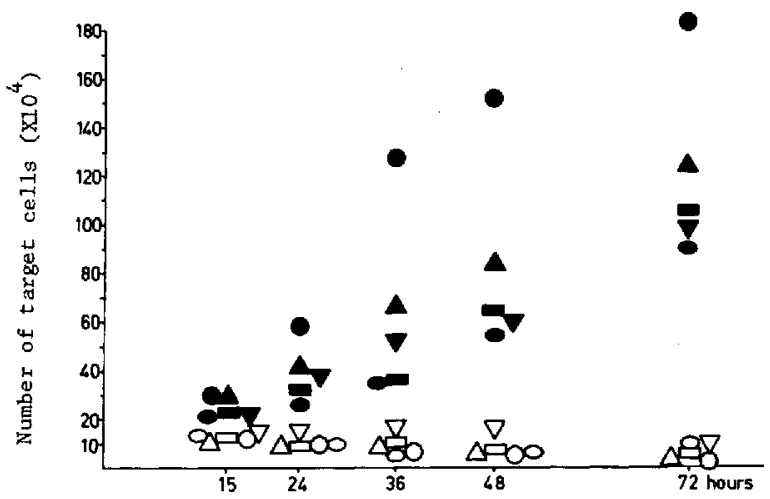

TEXT-FIGURE 1.-Decrease in number of neoplastic and normal target cells (initially $2 \times 105$ ) during interaction with macrophages $\left(2 \times 10^{4}\right)$. Target cell lines: $\square=\mathrm{DMB}$-induced DA rat tumor cells; $\triangle=$ polyoma-induced DA rat tumor cells; $O=$ mouse SV403T3 cells; $\bigcirc=$ mouse 3T3 fibroblasts; $\nabla=\mathrm{CHO}$ hamster fibroblasts. Closed symbols are targets alone; open symbols are targets in the presence of AM.
TARLE 3.-Differing effects by $A M$ on capacity of normal and transformed targets to reestablish growth

\begin{tabular}{cc} 
Target cell lines & Cloning efficacy $a$ \\
\hline $\mathrm{NRK}$ & $53( \pm 9)$ \\
$\mathrm{B}_{77}$ & $35( \pm 6)$ \\
$t s, 38^{\circ} \mathrm{C}$ & $22( \pm 9)$ \\
$t \mathrm{~s}, 33^{\circ} \mathrm{C}$ & $29( \pm 6)$ \\
\hline
\end{tabular}

a Percent of control as represented by the capacity for ${ }^{3} \mathrm{H}-\mathrm{TDR}$ incorporation. Values are means ( $1 \mathrm{sD}$ ) of 10 determinutions.

cells were equally affected, irrespective of whether or not they were permissive.

Experiments, in which loss of capacity to reestablish growth after prolonged culture with AM was taken as a measure of macrophage-mediated cytocidal target cell effects, revealed a significant cloning reduction in all cell lines examined (table 3). However, cytocidal effects were most pronounced in transformed cells, and no difference occurred between cells grown under permissive or nonpermissive conditions.

It was recently shown that the fusion of highly malignant mouse cells with normal cells or cells of low malignancy yiclds a hybrid with suppressed malignant characteristics (14). Among such hybrids, the A9 series is particularly interesting since hybrids with the slightly malignant L-cell subline showed suppressed malignancy, but partners of the highly malignant L-cell subline retained undiminished malignancy (13). Thus it appeared that a comparison between pairs of A9, A9HT, and the various $A 9$-tumor hybrids might give information relevant to the present issue.

Accordingly, the macrophage effects on five paired lines consisting of a slightly malignant (A9) and highly malignant (A9HT) counterpart were assessed. The data in text-figure 2 show that in every cell line examined, interaction with AM resulted in a marked diminution of ${ }^{3} \mathrm{H}$-TDR incorporation. However, when compared with most previously examined cell lines, several L-cell hybrids were surprisingly resistant to macrophage-mediated cytostasis; this became especially evident after 4 and 15 hours. After this interval, proliferation of a few cell lines was even stimulated by AM. Again, the susceptibility of the cell lines to macrophage-mediated cytostasis seemed independent of the degree of malignancy.

When macrophage-mediated cytocidal effects were assessed by an enumeration of the targets remaining after various intervals, all cell lines were comparably affected (text-fig. 3). In the absence of effectors, the cell numbers increased progressively; however, in their presence, cell numbers remained low and decreased as interaction proceeded (table 4). Again, no clear distinction was found in the susceptibility of cells with low or high malignancy within each comparable pair.

TABLE 2.-Correlation between degree of macrophage-mediated cytostasis and growth characteristics of different rat cell lines

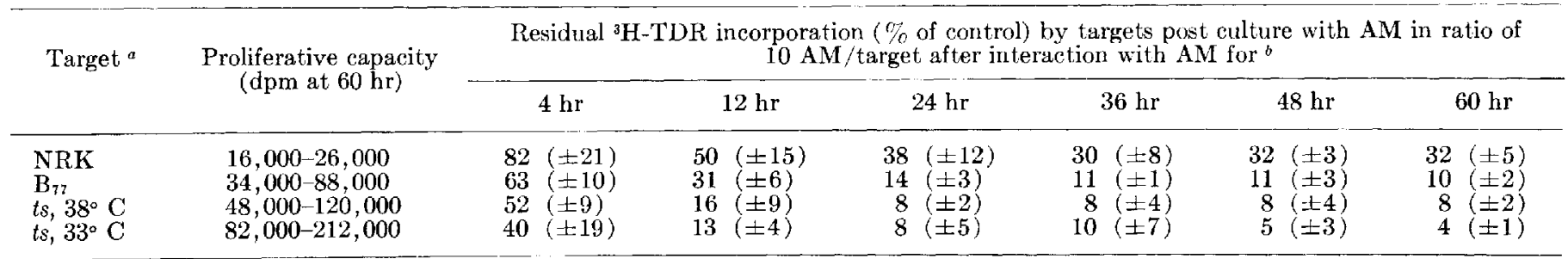

- $\mathrm{B}_{77}=\mathrm{NRK}$ cells infected with $\mathrm{B}_{73}$ avian sareoma virus; $t s=\mathrm{NRK}^{r}$ cells infected with temperature-sensitive mutant $t s 339$, permissive at $33^{\circ} \mathrm{C}$ and reverted to a normal phenotype at $38^{\circ} \mathrm{C}$.

$\checkmark$ Values represent means ( $\pm \mathbf{s}$ ) ) of 10 determinations. 


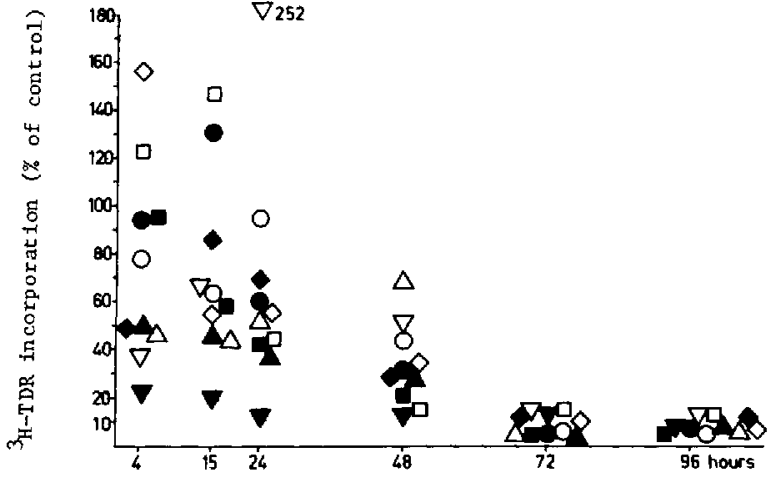

Text-Figure 2.--Macrophage-mediated $\left(2 \times 10^{6}\right)$ inhibition of target cell $\left(2 \times 10^{5}\right)$ proliferation is not dependent on degree of tumorigenicity. Target cell lines: $=$ A9; $O=A 9 H T ; \quad \nabla=A 9 /$ SEWA $\nabla=A 9 H T /$ SEWA; $\square=A 9 /$ MSWBS; $\square=A 9 H T /$ MSW BS; $\Delta=A 9$ YACIR; $\triangle=$ A9HT/YACIR; $\quad=$ A9/EA; $\diamond=$ A9HT $/$ EA. Closed symbols are slightly malignant derivatives; open symbols are highly malignant derivatives.

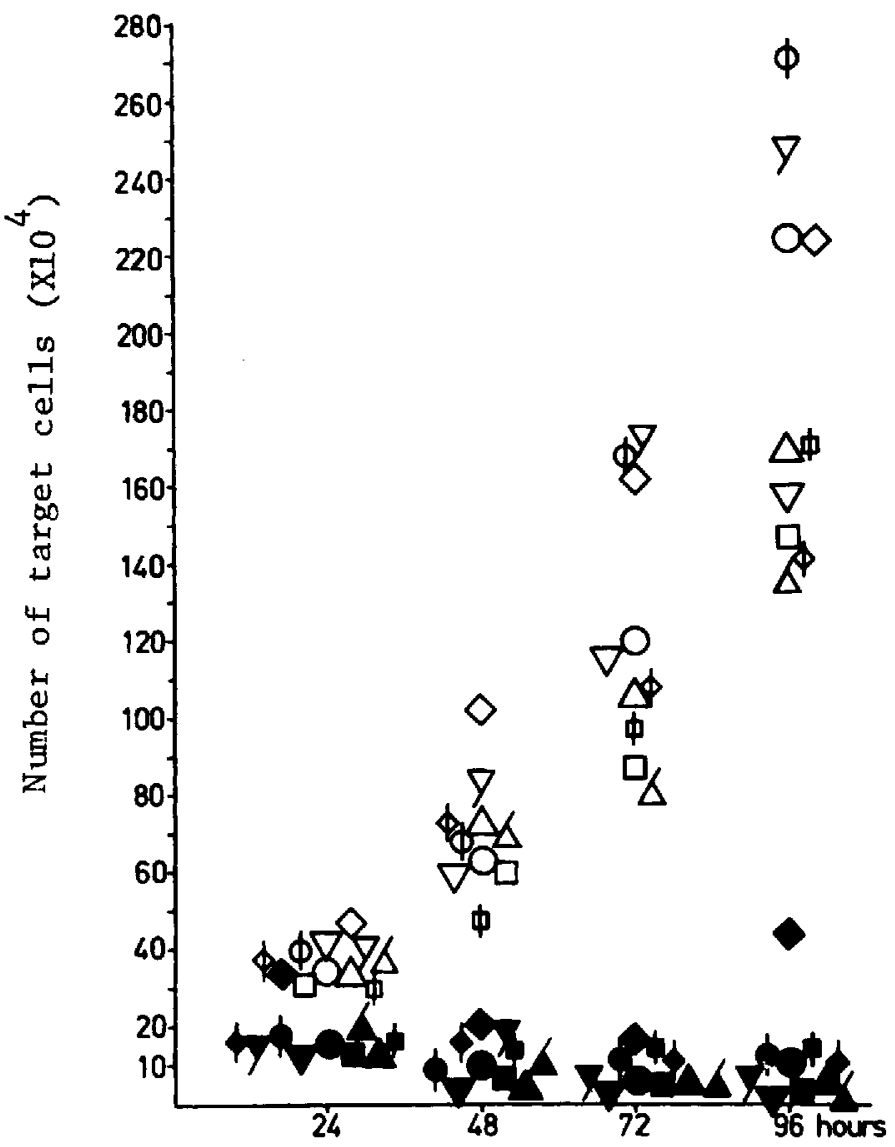

TEXT-FIGURE 3.-In pairs of $\mathrm{L}$-cell derivatives with low (A9) and high (A9HT) tumorigenicity, the number of targets (initially $2 \times 10^{5}$ ) was similarly affected during interaction with $2 \times 10^{6} \mathrm{DA}$ rat macrophages. Target cell lines: $O=A 9 ; \quad \nabla=A 9 /$ SEWA; $\square=$ A9 $/$ MSWBS: $\triangle=$ A9 $/$ YACIR; $\diamond=$ A9 $/ \mathbf{E A} ; \phi=$ A9HT: $\nabla=$ A9HT

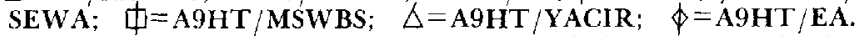
Open symbols are targets alone; closed symbols are targets in the presence of $\mathrm{AM}$.

\section{Cytocidal Effects Mediated by Macrophages}

Among the cell lines suitable for cytocidal experiments (i.e., those which incorporated and subsequently retained an appropriate amount of ${ }^{125}$ IUDR), considerable differences were seen in label retention. Some cell lines, e.g., RAJI, RPMI 7932, SK-OS, or polyoma virus-induced rat
TABLE 4.-Effect of AM on capacity of pairs of targets of low and high tumorigenicity to reestablish gronoth

\begin{tabular}{|c|c|}
\hline Tumorigenicity & Number of targets ${ }^{a}$ \\
\hline \multicolumn{2}{|l|}{ Low: } \\
\hline A9 $\ldots \ldots$ & 14 \\
\hline $\mathrm{A} 9 / \mathrm{MSWBS}$ & 4 \\
\hline A9/SEWA & 2 \\
\hline $\mathrm{A} 9 / \mathrm{EA}$ & 14 \\
\hline A9/YACIR _ . & 7 \\
\hline \multicolumn{2}{|l|}{ High: } \\
\hline A9HT & 13 \\
\hline A9HT/MSWBS $\ldots \ldots$ & 12 \\
\hline A9HT/SEWA & 9 \\
\hline $\mathrm{A} 9 \mathrm{HT} / \mathrm{EA} \ldots$ & 11 \\
\hline A9HT/YACIR _..... & 1 \\
\hline
\end{tabular}

a Absolute No. of targets ( $\times 10^{4} ;$ initially $2 \times 10^{5}$ ) remaining in culture after $96-1$, interaction with AM.

tumor cells, retained a high proportion of the label for at least 48 hours, whereas others (especially MEL-1, BEN, BT-20, and rat fibroblasts) often showed considerable spontaneous release. This leakage is probably an expression of ${ }^{125}$ IUDR- and/or FUDR-mediated toxicity. Although these differences in resistance to the labeling procedure may considerably affect the outcome of cytocidal tests, the measurements of the label release from target cells proved reproducible and provided information. The results in table 5 show that macrophagemediated release of ${ }^{125}$ IUDR from prelabeled target cells was consistently observed after 18 hours; after an 8-hour interaction, no such release was detectable. In many cell lines, and most evident in those with low spontaneous release (RPMI 7932, SK-OS, and RAJI), specific release increased as interaction proceeded. However, other cell lines including P-815, MEL-1, 3T3, SV403T3, BT-20, BEN, MPZ-2, MPZ-4, and CLA-4, were also susceptible to cytocidal macrophage effects. No difference was discerned between "normal" 3T3 fibroblasts and their virustransformed counterparts. Among the cells examined, recently explanted syngeneic rat fibroblasts and DMBAinduced syngeneic rat tumors were resistant; cytocidlal effects were not consistently detectable.

A comparison of cytostatic and cytocidal macrophage effects on these targets (tables 1, 5) indicates that the

TABLE 5.-Susceptibility of various taryet cell lines to macrophage-medialed cytocidal effects

\begin{tabular}{|c|c|c|c|c|c|c|}
\hline \multirow[t]{2}{*}{ Cell line } & \multicolumn{6}{|c|}{$\begin{array}{l}\text { Percent of sytocidal activity effected } \\
\qquad\left({ }^{125} \text { JUDR release) at }{ }^{a}\right.\end{array}$} \\
\hline & & $18 \mathrm{hr}$ & & $36 \mathrm{hr}$ & & $48 \mathrm{hr}$ \\
\hline \multicolumn{7}{|l|}{ Fibroblasts } \\
\hline $\begin{array}{l}\text { Passages 4-7 } \\
\text { Passages 24-30.... }\end{array}$ & 15 & $( \pm 14)$ & & $( \pm 7)$ & 8 & $(-17)$ \\
\hline $\begin{array}{l}\text { Passages 24-30 } \\
\text { Polyoma }\end{array}$ & 17 & $( \pm 8)$ & 19 & $( \pm 12)$ & 21 & $( \pm 9)$ \\
\hline Polyoma......... & 5 & $( \pm 5)$ & 9 & $( \pm 6)$ & 21 & $( \pm 10)$ \\
\hline MCA & 14 & $( \pm 16)$ & 12 & $( \pm 9)$ & 12 & $( \pm 8)$ \\
\hline DMBA & 9 & $( \pm 5)$ & 9 & $( \pm 6)$ & 8 & $( \pm 15)$ \\
\hline $3 \mathrm{~T} 3 \ldots$ & 13 & $( \pm 5)$ & 9 & $( \pm 9)$ & 10 & $( \pm 8)$ \\
\hline SV403T3 & 16 & $( \pm 4)$ & 23 & $( \pm 5)$ & 16 & $( \pm 5)$ \\
\hline P-815 ... & 20 & $( \pm 5)$ & 28 & $( \pm 10)$ & 28 & $( \pm 4)$ \\
\hline $\mathrm{RAJI}_{--}$ & 3 & $( \pm 3)$ & 30 & $( \pm 7)$ & 37 & $( \pm 7)$ \\
\hline CLA-4 & 6 & $( \pm 4)$ & 17 & $( \pm 9)$ & 18 & $( \pm 7)$ \\
\hline MEL-1 $\ldots$ & 23 & $( \pm 8)$ & 38 & $( \pm 6)$ & 4.5 & $( \pm 5)$ \\
\hline RPMI 7932 & 11 & $( \pm 4)$ & 44 & $( \pm 10)$ & 50 & $( \pm \pi)$ \\
\hline BEN & 3 & $( \pm 3)$ & 10 & $( \pm 10)$ & 13 & $( \pm 17)$ \\
\hline $\mathrm{SK}-\mathrm{OS}$ & 23 & $( \pm 4)$ & 48 & $( \pm 10)$ & 48 & $( \pm 7)$ \\
\hline BT- 20. & 20 & $( \pm 6)$ & 49 & $( \pm 17)$ & 59 & $( \pm 6)$ \\
\hline MPZ-2 & 30 & $( \pm 11)$ & 28 & $( \pm 11)$ & 26 & $( \pm 6)$ \\
\hline MPZ-4 & 9 & $( \pm 6)$ & 12 & $( \pm 7)$ & 12 & $( \pm 6)$ \\
\hline
\end{tabular}

- Values are means ( $\pm \mathrm{gD}$ ) of 10-15 experiments, each performed in triplicate. 
changes in these parameters during interaction were not consistently parallel. A close parallelism in the degree and time course of cytostatic and cytocidal manifestations was especially notable in the lymphoblastoid lines RAJI and CLA-4 and in rat fibroblasts. However, no such parallelism in cytostatic and cytocidal effects was seen in polyoma virus-induced DA rat tumor and P-815 mouse mastocytoma cells.

\section{DISCUSSION}

Prior in vitro studies $(4,6)$ in this laboratory consistently demonstrated that interaction of macrophages with targets first affects target cell proliferation and is often accompanied by a decrease in the number of targets; the capability of remaining targets to reestablish growth was diminished. These studies led to the provisional conclusion that macrophage-mediated cytostasis transcends species, cell type, and growth characteristics and is exerted on all rapidly replicating cells, whether derived from normal or transformed tissues $(4-7)$. The data reported here encompass more target cell lines and show that prolonged interaction with a majority of macrophages (effector to target cell ratio is $10: 1$ ) results in a distinct inhibition of target cell proliferation in every cell line examined, but the degree of cytostasis evoked by macrophages differs markedly from one cell line to another. The results were similar irrespective of whether ${ }^{3} \mathrm{H}-\mathrm{TDR}$ or ${ }^{125}$ IUDR was used as a pulse label to assess the residual proliferative capacity. Since macrophages do not replicate under tissue culture conditions and remain in the $G_{1}$ or $G_{0}$ phase of the cell cycle, incorporation of these labels is sharply restricted to target cells.

The data once again demonstrate that there are major differences in the susceptibility of cell lines. When a large array of cell lines is ranked by their susceptibility to macrophage-mediated cytostasis, normal replicating lymphoid cells (7), various virus-transformed lines (rat polyoma and $B_{77}$, mouse SV40), P-815 mouse mastocytoma cells, and some cell lines derived from human malignant tumors are especially sensitive; derivatives of the mouse $\mathrm{L}$ fibroblast, though consistently blocked after prolonged interaction with macrophages, showed large differences in their initial sensitivity not correlated with their degree of malignancy. Other lines such as 3T3, CHO, DMBAand MCA-induced rat tumor cells, the lymphoblastoid cell lines, and recently explanted fibroblasts derived from normal adult or embryonic DA rat tissue, were resistant to macrophage-mediated cytostasis. Accordingly, it is evident that in rapidly replicating cell lines, factors other than capacity for in vivo malignancy or in vitro transformation determine susceptibility to macrophagemediated cytostasis.

Earlier studies (4) showed that indicators of immune cytotoxicity such as those widely employed in lymphocytetarget studies (i.e., release of ${ }^{51} \mathrm{Cr}$ or uptake of trypan blue) were unsuitable for detection of macrophageinduced changes in target cell viability. Accordingly, in some experiments, the number of target cells remaining after various intervals of interaction with macrophages was counted for quantitation of cytocidal macrophage effects on targets; the number of remaining targets shows some diminution by 24 hours and is further decreased as the interaction proceeds. However, many targets often remain in culture even after a 96-hour interaction with macrophages (table 4).

${ }^{125}$ IUDR has been used more frequently as a Iabel of target cells for the detection of lymphocyte-mediated cytotoxicity $(17-21)$. The main advantages of ${ }^{125} \mathrm{IUDR}$ are low spontaneous release and little, if any, reutilization. Accordingly, release of the isotope from prelabeled targets indicates cell death and 1ysis (22-25); since ${ }^{125}$ IUDR is a gamma-emitting isotope, little preparation of samples is needed before counting. However, ${ }^{125}$ IUDR is toxic $(26,27)$ and often blocks further cell replication. The present studies show, however, that despite considerable differences among the various cell lines, toxicity contributed by the labeling procedure can be held within acceptable limits, provided the isotope concentration is kept low and incubation is limited to 8 hours. Under such conditions, the inclusion of FUDR to increase preferentially the incorporation of IUDR into DNA in place of ${ }^{3} \mathrm{H}-\mathrm{TDR}$ is a necessary precondition. With the use of these modifications, target cell lines were sufficiently labeled without gross signs of toxicity; i.e., ${ }^{125}$ IUDRlabeled cells replicated at a rate similar to that of unlabeled controls. Thus the present work shows that this method of measuring cytocidal (and cytostatic) capacities of effectors applies to targets long established in culture or recently derived from normal tissues, growing adherent or in suspension, or showing growth attributes typical of normal or transformed cells.

The accurate measurement of viability in a variety of targets and its application to macrophage-mediated effects are essential for furthering the understanding of the processes involved in the interaction between macrophages and other eukaryote cells. Our work clearly demonstrates that interaction of nonimmune macrophages with a variety of prelabeled targets is accompanied by a consistent release of the label. Such release is not usually detectable before 18 hours, but often increases as interaction proceeds. Beyond the principal demonstration of the existence of the potent cytocidal or cytolytic capacities of nonimmune macrophages, the present findings, though still limited, are informative in many ways. Thus the data indicate distinct differences among the targets examined in their susceptibility to macrophage-mediated cytocidal effects. For example, carcinogen-induced tumor cells and recent explants of normal fibroblasts, both of syngeneic origin, seem particularly resistant.

On the basis of morphologic grading of macrophagemediated target cell cytotoxicity, neoplastic cells are uniquely susceptible as contrasted to their normal counterparts $(3,4,10)$. However, both previous $(6,28,29)$ and present findings showing that transformed cells are affected equally whether they are grown at permissive or nonpermissive temperatures, or whether they differ considerably in their malignant potential, now indicate that the prior conclusions were overgeneralized. These data and especially those about recent explants of rat fibroblasts indicate a quantitative rather than a qualitative difference in susceptibility of normal and transformed targets to macrophage-mediated cytocidal effects. Further studies with cells recently derived from normal tissues (especially primary explants) are necessary to clarify this issue.

In many target cell lines, macrophage-mediated cytostatic and cytocidal effects showed considerable parallelism. For example, recent explants of DA rat fibroblasts and carcinogen-induced DA rat cell lines, as well as human lymphoblastoid lines, were relatively resistant to both effects. However, in polyoma-induced rat and P-815 mouse cells, no such parallelism was observed; these cell lines were highly susceptible to cytostatic macrophage effects but resistant to cytocidal macrophage effects. This discrepancy suggests that cytostatic and cytocidal effects 
are not necessarily closely related. Earlier works $(5,7,30)$ have convincingly shown that the effects on cell proliferation, both enhancing and blocking, are mediated by soluble factors released from macrophages in in vitro culture. However, close contact with targets seems necessary for cytocidal and/or cytolytic effects of macrophages (31).

Most of the present comparative studies have been performed in parallel with the same macrophage populations for all targets. This is important since comparisons of results of series of experiments have repeatedly disclosed large quantitative differences $(6,7)$. Such differences as previously observed in macrophage cytostatic activity were probably sometimes due to differing degrees of macrophage functional activities. Similarly, the present variability in cytostatic (table 1) and cytocidal (table 5) macrophage-mediated effects is mainly due to variations in activity manifested by macrophages harvested from different groups of inbred DA rats. Other variables, e.g., target cell characteristics, did not significantly affect the outcome of the interaction. The quantitative differences encountered in the degree of macrophage-mediated cytostasis and cytolysis did not prejudice the principal conclusions discussed earlier.

Interpretation of the present findings is further complicated by the likelihood that most of the lines generally utilized as representative of "normal" cells, such as 3T3 or CHO cells, are not the unaltered host cells we seek. In this respect, recent findings demonstrating that inoculation of the "normal" BALB/c3T3 cell line attached to glass beads leads to malignant hemangioendotheliomas, are significant (32). Thus we have reasons for believing that the currently accepted view that postconfluence inhibition of cell division, low saturation density, and anchorage dependence are in vitro properties characteristic only of normal nonmalignant cells, should now be reassessed. These developments imply that eukaryotic cells once established as cell lines (i.e., no longer under host regulatory control) have the potential for malignancy. Accordingly, the findings obtained with established cell lines in vitro are not the direct and extrapolatable information as previously viewed.

Despite these ambiguities, one salient point does emerge. Among a larger number of transformed cell lines with considerably differing malignant potential, there is no correlation between the degree of transformation and the susceptibility to macrophage cytocidal effects.

\section{REFERENCES}

(I) Keller R, Jones VE: Role of activated macrophages and antibody in inhibition and enhancement of tumour growth in rats. Lancet 2:847-849, 1971

(2) Alexander P, Evans R: Endotoxin and double-stranded RNA render macrophages cytotoxic. Nature [New Biol] 232:76 78,1971

(3) HibBs JB, LAmbert LH, Remington JS: Macrophage mediated nonspecific cytotoxicity-possible role in tumour resistance. Nature [New Biol] 235:48-50, 1972

(4) Keller R: Cytostatic elimination of syngeneic rat tumor cells in vitro by nonspecifically activated macrophages. J Exp Med 138:625-644, 1973

(5) - - Cytostatic and cytocidal effects of activated macrophages. In Immunobiology of the Macrophage, (Nelson DS, ed.). New York, Academic Press, 1976, chapt 19

(b) - Modulation of cell proliferation by macrophages: A possible function apart from cytotoxic tumour rejection. Br J Cancer 30:401-415, 1974

(7) - Major changes in lymphocyte proliferation evoked by activated macrophages. Cell Immunol 17:542-551, 1975
(8) - Beziehungen zwischen Tumorwachstum und Immunität. Schweiz Med Wochenschr 102:1148-1151, 1972

(9) HibBs JB: Macrophage nonimmunologic recognition: Target cell factors related to contact inhibition. Science 180:868870,1973

(10) Holtermann OA, Krein E, Casate GP: Selective cytotoxicity of peritoneal leukocytes for neoplastic cells. Cell Immunol 9:339-352, 1973

(1I) Graf T, FrIIs RR: Differential expression of transformation in rat and chicken cells infected with an avian sarcoma virus ts mutant. Virology 56:359-374, 1973

(12) EaGle H: Amino acid metabolism in mammalian cell culture. Science 130:432-437, 1959

(13) Klein G, Bregula U, Wuener R, et al: The analysis of malignancy by cell fusion. I. Hybrids between tumour cells and $L$ cell derivatives. J Cell Sci 8:659-672, 1971

(14) Wiener F, Klein G, Harris $H$ : The analysis of malignancy by cell fusion. IV. Hybrids between tumour cells and a malig. nant $L$ cell derivative. J Cell Sci 12:253-261, 1973

(15) Schindler R, DAy M, Fischer GA: Culture of neoplastic mast cells and their synthesis of 5 -hydroxytryptamine and histamine in vitro. Cancer Res 19:47-51, 1959

(16) Haktmann KU, Heidelgerger C: Studies on fluorinated pyrimidines. XIII, Inhibition of thymidylate synthetase. J Biol Chem 236:3006-3013, 1961

(17) Cohen AM, Burdick JF, Ketcham AS: Cell-mediated cytotoxicity: An assay using 125I-iododeoxyuridine-labeled target cells. J Immunol 107:895-898, 1971

(18) SEeger RC, Owen JJ: Measurement of tumor immunity in vitro with 12:I-iododeoxyuridine-labeled target cells. Transplantation 15:404-408, 1973

(19) SEEger RC, RAyner SA, OWEN JJ: An analysis of variables affecting the measurement of tumor immunity in vitro with 125I-iododeoxyuridine-labeled target cells. Studies of immunity to primary Moloney sarcomas. Int J Gancer 13:697713,1974

(20) Le Mevel BP, Wells SA: A microassay for the quantitation of cytotoxic antitumor antibody: Use of 125I-iododeoxyuridine as a tumor cell label. J Natl Cancer Inst 50:803-806, 1973

(21) Oldham RK, Herberman RB: Evaluation of cell-mediated cytotoxic reactivity against tumor associated antigens with 125I-iododeoxyuridine-labeled target cells. J Immunol 111: $1862-1871,1973$

(22) Oldham RK, Srwarski D, MCCoy JL, et al: Evaluation of a cell-mediated cytotoxicity assay utilizing 125I-iododeoxyuridine-labeled tissue-culture target cells. Natl Cancer Inst Monogr 37:49-58, 1973

(23) Hughes WL, Commerford SL, Gitlin D, et al: Deoxyribonucleic acid metabolism in vivo. 1 . Cell proliferation and death as measured by incorporation and elimination of iododeoxyuridine Fed Proc 23:640-648, 1964

(24) Eidinoff ML, Cheong L, Rich MA: Incorporation of unnatural pyrimidine bases into deoxyribonucleic acid of mammalian cells. Science 129:1550-155i, 1959

(25) Heiniger HJ, Freidrich G, Freinendegen LE, et al: Reutilization of 5-125I-iodo-2'-deoxyuridine and 3 H-thymidine in regenerating liver of mice. Proc Soc Exp Biol Med 137:13811384, 1971

(26) Mathias AP, Fischer GA, Prusoff WH: Inhibition of the growth of mouse leukemia cells in culture by 5 -iododeoxyuridine. Biochim Biophys Acta 36:560-561, 1959

(27) Jaffe JJ, Prusoff WH: The effect of 5-iododeoxyuridine upon the growth of some transplantable rodent tumors. Cancer Res 20:1383-1388, 1960

(28) Cleveland RP, Meltzer MS, ZBar B: Tumor cytotoxicity in vitro by macrophages from mice infected with $M y c o$ bacterium bovis strain BCG. I Natl Cancer Inst 52:18871895,1974

(29) Kaplan AM, Morahan PS, Regelson W: Induction of macrophage-mediated tumor-cell cytotoxicity by pyran copolymer. J Natl Cancer Inst 52:1919-1923, 1974

(30) Calderon J, Williams RT, Unanue ER: An inhibitor of cell proliferation released by cultures of macrophages. Proc Natl Acad Sci USA 71:4273-4277, 1974

(31) HibBs JB: Heterocytolysis by macrophages activated by bacillus Calmette-Guérin: Lysosome exocytosis into tumor cells. Science 184:468-471, 1974

(32) BoONE CW: Malignant hemangioendotheliomas produced by subcutaneous inoculation of BALB/3T3 cells attached to glass beads. Science 188:68-70, 1975 